\title{
Letter
}

\section{COVID-19 associated Mucormycosis (CAM): Should Brazil be on alert?}

\author{
Luís Arthur Brasil Gadelha Farias ${ }^{[1],[2], ~ L i s a n d r a ~ S e r r a ~ D a m a s c e n o ~}{ }^{[2],[3],}$ \\ Silviane Praciano Bandeira ${ }^{[4]}$, Francisca Kalline de Almeida Barreto ${ }^{[3]}$, \\ Terezinha do Menino Jesus Silva Leitão ${ }^{[2],[3]}$ and Luciano Pamplona de Góes Cavalcanti ${ }^{[3],[4],[5]}$
}

\author{
[1]. Escola de Saúde Pública do Ceará, Fortaleza, CE, Brasil. \\ [2]. Hospital São José de Doenças Infecciosas, Fortaleza, CE, Brasil. \\ [3]. Universidade Federal do Ceará, Faculdade de Medicina, Departamento de Saúde Comunitária, Fortaleza, CE, Brasil. \\ [4]. Universidade Federal do Ceará, Faculdade de Medicina, Departamento de Patologia e Medicina Legal, Fortaleza, CE, Brasil.
}

[5]. Centro Universitário Christus, Faculdade de Medicina, Fortaleza, CE, Brasil.

Dear Editor:

Mucormycosis is an emerging fungal infection that induces a life-threatening disease caused by zygomycetes belonging to the order Mucorales. There are several genera in this group of fungi. The most important are the Rhizopus sp., Mucor sp., Rhizomucor sp., Syncephalastrum sp., and Lichtheimia sp. The zygomycetes group was identified based on morphological characteristics including fungal hyphae typical for mucormycetes in biopsies of affected tissues or bronchoalveolar lavage, direct microscopy on $\mathrm{KOH}$, and culture identification with antifungal susceptibility test. However, identification at the species level is difficult ${ }^{1-4}$. Molecular-based methods may be applied to tissues for species identification. Other method such as matrix-assisted laser desorption ionization-time of flight mass spectrometry for the identification of cultured Mucorales is promising; however, more validated data are needed. Thus, molecular identification remains the gold standard ${ }^{3,4}$.

The zygomycetes are hyaline filamentous fungi with coenocytic and broad hyphae with branches oriented at $90^{\circ}$, and septations are rarely observed (Figure 1). In the culture media, they are characterized by grayish colonies with abundant mycelia. These saprophytic microorganisms thrive in soil, decaying organic matter, fruits, and starchy foods. Inhalation of fungal spores results in the colonization of the human airways ${ }^{1,3,4}$.

\footnotetext{
Corresponding author: Dr. Luís Arthur Brasil Gadelha Farias.

e-mail: luisarthurbrasilk@hotmail.com

(D) https://orcid.org/0000-0002-8978-9903

Received 20 July 2021

Accepted 6 August 2021
}

Brazil is responsible for most published cases of mucormycosis in Latin America (Brazil, 59; Argentina, 36; Chile, 14; Colombia, 22; Venezuela, 7; Peru, 3; and Ecuador and French Guiana, 1 case each) as identified by Nucci M. et al ${ }^{5}$. Patients with mucormycosis from Brazil were predominantly male $(n=37 ; 62.5 \%)$ with a median age of $43(<1-78)$ years. The most common underlying conditions of the affected individuals include diabetes mellitus (42.4\%), solid organ transplant (22.9\%), and malignancy (16.9\%). In Brazil, the mortality rate of mucormycosis was higher $(52.5 \%)$ than overall mortality due to other reasons (48.3\%); it was also higher than the mortality rates of mucormycosis reported from other countries (45.2\%). The identified genera from Brazil included Rhizopus sp. $(\mathrm{n}=11 ; 18.6 \%)$, Mucor $\mathrm{sp} .(\mathrm{n}=7 ; 11.9 \%)$, and rarely Rhizomucor $\mathrm{sp}$. $(\mathrm{n}=2 ; 3.5 \%)$, and Lichtheimia $\mathrm{sp} .(\mathrm{n}=2 ; 3.5 \%)^{5}$.

Although mucormycosis is a rare invasive fungal infection, its emergence has increased during the coronavirus disease-2019 (COVID-19) pandemic ${ }^{1,2}$. In particular, the occurrence of fungal infections, such as Candida sp. and Aspergillus sp. co-infections has increased during the pandemic ${ }^{2,6}$. The burden of mucormycosis in India emphasizes the high incidence of lethal fungal infections and its implications for public health ${ }^{7-10}$.

According to the World Health Organization (WHO), 28,307,832 COVID-19 cases and 335,102 deaths from COVID-19 were reported in India in June 20217. The emergence of COVID-19-associated mucormycosis (CAM) is not coincidental. The main risk factors may be the high incidence of diabetes in the country's population (many without diagnosis and treatment), favoring the outbreak of mucormycosis in hospitalized intensive care unit patients receiving high-dose corticosteroids for COVID-19 treatment ${ }^{1,2}$. 


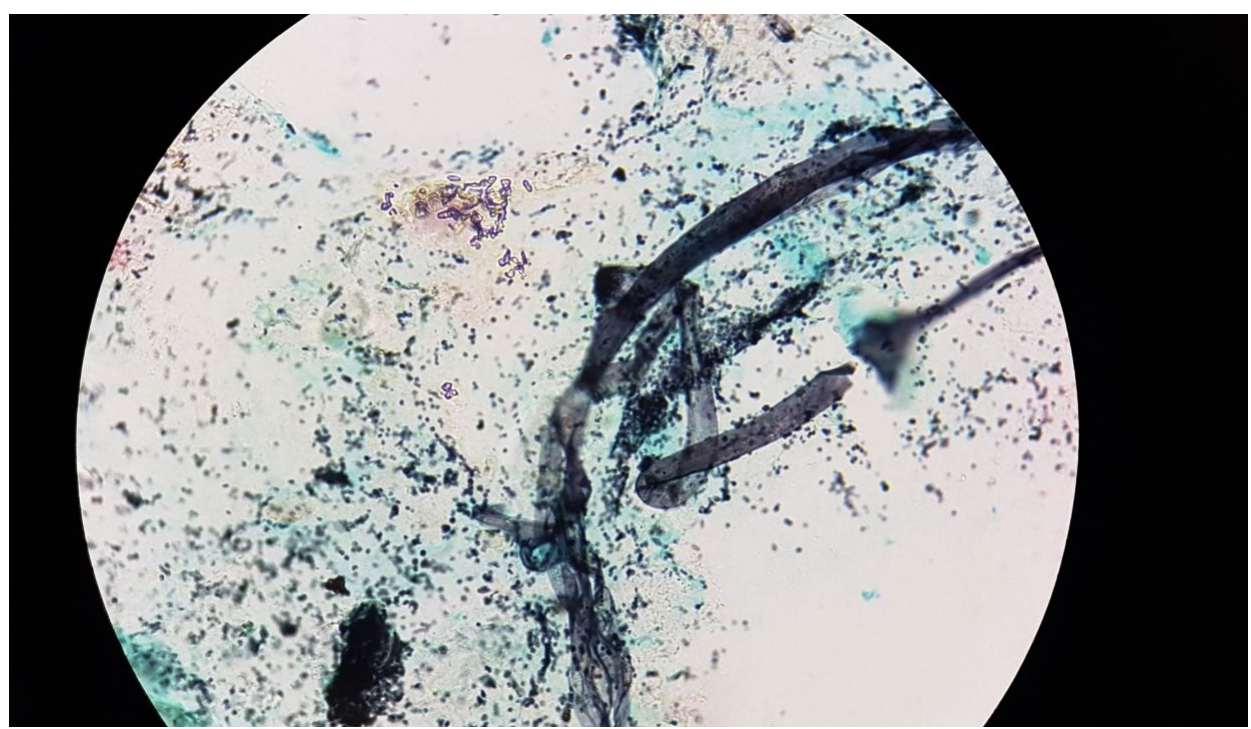

FIGURE 1: Broad and coenocytic hyphae in paranasal sinus content biopsy (Gomori methenamine silver - 1000x).

Mucormycosis outbreaks in India were initially reported by ophthalmology professionals during the COVID-19 pandemic ${ }^{8}$. As a part of COVID-19 treatment, diabetes patients received increased corticosteroids, leading to uncontrolled glucose levels, resulting in a fertile ground for the Mucorales fungi. John et al. identified 43 cases of mucormycosis in COVID-19 patients and found that 33 of 35 (94\%) patients had documented glycemic status representative of diabetes ${ }^{9}$. In a recent retrospective study by Patel et al., uncontrolled diabetes was the most common underlying disease among COVID-19 patients admitted from September 2020 to December 2020, including 187 patients with CAM. Other factors included hematologic malignancy and $\mathrm{SOT}^{10}$.

Diabetes increases the risk of worse outcomes in patients infected with severe acute respiratory syndrome-coronavirus- $2^{11-13}$. Thus, the need for hospitalization has increased due to the high number of patients with diabetes in Brazil ${ }^{13}$. The prevalence of diabetes is approximately $11.5 \%$, and most patients are between 20 and 69 years of age. Moreover, these patients commonly have uncontrolled hyperglycemia ${ }^{12}$. In a study conducted in Brazil, diabetes patients with COVID-19 were more frequently admitted to the intensive care units (18\%). Specifically, they were 1.34 times more likely to require hospitalization $(1.10-1.61, \mathrm{p}=0.003)^{13}$. Furthermore, the hyperinflammation generated by COVID-19 makes glycemic control difficult. There has been one reported death attributed to mucormycosis in a 56-year-old man with diabetic ketoacidosis from Manaus, Amazonas, located in northern Brazil ${ }^{14}$.

Although mucormycosis has been prevalent in India $(71 \%$ of global cases), some cases have also been reported in Brazil ${ }^{14,15}$. According to PAHO/WHO, seven American (USA, Mexico, Brazil, Chile, Honduras, Paraguay, and Uruguay) countries have reported confirmed CAM cases ${ }^{15}$.

To standardize the surveillance and control of invasive fungal infections related to COVID-19, Anvisa published a technical note (GVIMS/GGTES/ANVISA N ${ }^{\circ}$ 04/2021) with the diagnostic criteria for suspected mucormycosis. The criteria included decompensated diabetes patients diagnosed with severe COVID-19, who were administered steroids during or after COVID-19 and had acute/ subacute sinusitis, with imaging documentation of sinusitis and at least one of the following signs: (1) early: acute and localized (including pain radiating to the eye) pain, fever, impaired general condition, and severe facial pain; or (2) delayed: nasal ulcer with black exudate, nasal bleeding, facial edema, asymmetries, eye pain, eyelid ptosis, visual changes, amaurosis, freezing of eye movements, and necrosis around the nose. Mycosis can extend to the paranasal sinus and bone barriers, including the orbit and the palate, as well as affecting the central nervous system via abscess formation ${ }^{16}$. Other differential diagnoses that may involve progressive facial swelling, ulceration, and destruction must be excluded. Furthermore, mucormycosis may resemble orbital cellulitis, extranodal T-cell lymphoma, or cutaneous anthrax ${ }^{1}$.

With the emergence of new variants, it is crucial to prepare the public health system structurally and professionally, considering the repercussions of zygomycete infections in India. The delta COVID-19 variant (B.1.617.2), first detected in India, has spread to other countries, such as the United Kingdom, and poses the risk of a new COVID-19 surge ${ }^{14}$. The emergence of new variants in Brazil has led to concerns among the health professional and scientific community regarding potential complications, including the impact of fungal infections on COVID-19 morbidity and mortality $1,8,17$.

Hospitals should be prepared to diagnose and treat serious fungal infections requiring surgery and make available expensive antifungal agents. Currently, treatment is based on a multimodal approach, including the control of underlying predisposing factors, early administration of active antifungal agents at optimal doses, and complete removal of any infected tissues. Ampotericin B lipid-based formulations formulations are the antifungal therapy of choice ${ }^{1,6,14,16}$. Other antifungal therapies such as posaconazole and isavuconazole are recommended alternatives ${ }^{16}$. Nonetheless, the health systems must be aware of and prepared to treat invasive fungal infections in the COVID-19 era. 


\section{ACKNOWLEDGMENTS}

We thank all professionals working in COVID-19 pandemic.

\section{AUTHORS' CONTRIBUTION}

LABGF: Conception, writing and approved the final manuscript. LSD, SPB, FKAB: Revision, final approval of the version to be submitted. TMJSL, LPGC: Conception of the study, supervision and analysis.

\section{CONFLICT OF INTEREST}

The authors declare that there is no conflict of interest.

\section{FINANCIAL SUPPORT}

None.

\section{ORCID}

Luís Arthur Brasil Gadelha Farias: 0000-0002-8978-9903

Lisandra Serra Damasceno: 0000-0003-1425-5912

Silviane Praciano Bandeira: 0000-0002-4051-5645

Francisca Kalline de Almeida Barreto: 0000-0001-9767-7154

Terezinha do Menino Jesus Silva Leitão: 0000-0002-3301-3057

Luciano Pamplona de Góes Cavalcanti: 0000-0002-3440-1182

\section{REFERENCES}

1. Jeong W, Keighley C, Wolfe R, Lee WL, Slavin MA, Kong DCM, et al. The epidemiology and clinical manifestations of mucormycosis: a systematic review and meta-analysis of case reports. Clin Microbiol Infect. 2019;25(1):26-34.

2. Song G, Liang G, Liu W. Fungal Co-infections Associated with Global COVID-19 pandemic: a clinical and diagnostic perspective from China. Mycopathologia. 2020;185(4):599-606.

3. Millon L, Scherer E, Rocchi S, Bellanger AP. Molecular Strategies to Diagnose Mucormycosis. J Fungi (Basel). 2019;5(1):24.

4. Walther G, Wagner L, Kurzai O. Updates on the Taxonomy of Mucorales with an Emphasis on Clinically Important Taxa. J Fungi (Basel). 2019;5(4):106.
5. Nucci M, Engelhardt M, Hamed K. Mucormycosis in South America: A review of 143 reported cases. Mycoses. 2019;62(9):730-8.

6. Santana MF, Pivoto G, Alexandre MAA, Baía-da-Silva DC, Borba MGDS, Val FA, et al. Confirmed Invasive Pulmonary Aspergillosis and COVID-19: the value of postmortem findings to support antemortem management. Rev Soc Bras Med Trop. 2020;53:e20200401.

7. World Health Organization (WHO). The current COVID-19 situation. India. Accessed on June 15: https://www.who.int/countries/ind/.

8. Sen M, Lahane S, Lahane TP, Parekh R, Honavar SG. Mucor in a viral land: a tale of two pathogens. Indian J Ophthalmol. 2021;69(2):244-52.

9. Moorthy A, Gaikwad R, Krishna S, Hegde R, Tripathi KK, Kale PG, et al. SARS-CoV-2, uncontrolled diabetes and corticosteroids-an unholy trinity in invasive fungal infections of the maxillofacial region? A retrospective, multi-centric analysis. J Maxillofac Oral Surg. 2021:1-8.

10. Patel A, Agarwal R, Rudramurthy SM, Shevkani M, Xess I, Sharma R, et al. Multicenter epidemiologic study of coronavirus disease-associated mucormycosis, India. Emerg Infect Dis; 2021;27(9).

11. Jeronimo CMP, Farias MEL, Val FFA, Sampaio VS, Alexandre MAA, Melo GC, et al; Metcovid Team. Methylprednisolone as Adjunctive Therapy for Patients Hospitalized with Coronavirus Disease 2019 (COVID-19; Metcovid): A Randomized, Double-blind, Phase IIb, Placebo-controlled Trial. Clin Infect Dis. 2021;72(9):e373-e381.

12. Feldman EL, Savelieff MG, Hayek SS, Pennathur S, Kretzler M, PopBusui R. COVID-19 and diabetes: a collision and collusion of two diseases. Diabetes. 2020;69(12):2549-65.

13. Silva I, Faria NC, Ferreira ARS, Anastácio LR, Ferreira LG. Risk factors for critical illness and death among adult Brazilians with COVID-19. Rev Soc Bras Med Trop 2021;54:e0014. Available from: https://oi. org/10.1016/j.diabres.2020.108304

14. Bonates P, João GAP, Cruz KS, Ferreira MS, Baía-da-Silva DC, Farias MEL, et al. Fatal rhino-orbito-cerebral mucormycosis infection associated with diabetic ketoacidosis post-COVID-19. Rev Bras Med Trop. 2021;54:1-6.

15. Pan American Health Organization/World Health Organization. Epidemiological Alert: COVID-19 associated Mucormycosis. 2021, Washington, D.C.: PAHO/WHO; 2021.

16. ANVISA. Nota Técnica GVIMS/GGTES/ANVISA Nº 04/2021. Orientações para vigilância, identificação, prevenção e controle de infecções fúngicas invasivas em serviços de saúde no contexto da pandemia da COVID-19. 14 de Junho de 2021. P. 1-39.

17. Torjesen I. Covid-19: Delta variant is now UK's most dominant strain and spreading through schools. BMJ. 2021;373:n1445. 